\title{
Pesquisa em saúde, política de saúde e eqüidade na América Latina
}

\author{
Health research, health policy and equity \\ in Latin America
}

Alberto Pellegrini Filho 1

\footnotetext{
1 Unidade de Promoção e Desenvolvimento da Pesquisa, OPAS, 525, 23th Street, NW, Washington DC 20037, EUA. pellegri@paho.org
}

\begin{abstract}
The author analyzes the relationships between health research, health policies and equity in Latin America. He describes new trends in the mode of knowledge production that enhance the integration between social needs and research, facilitating the ties between research and the policy making process. The author also analyzes the manifestations of these new trends in Latin America, and describes some initiatives promoted by the PAHO aimed to take advantage of the opportunities opened by these trends to improve health conditions in the region. Throughout the article the author defends the thesis that information and knowledge are essential public goods and that the inequities in the access of these public goods are important determinants of health inequities. He also sustains that in order to integrate health policies and health research policies and consolidate them as public policies geared to serve the public interest and the promotion of equity, it is necessary to strengthening the democratic process in the definition of these policies, by multiplying the actors involved, as well as the spaces and opportunities for interaction among them, and by supporting their participation with equitable access to pertinent information and scientific knowledge.
\end{abstract}

Key words Equity, Research, Knowledge, Social participation, Health policy, Latin America
Resumo O autor analisa as relações entre pesquisa de saúde, políticas de saúde e eqüidade na América Latina. Descreve novas tendências no modo de produção do conhecimento, que permitem maior integração entre as necessidades sociais e a pesquisa, facilitando o vínculo entre esta e o processo de definição de políticas. Analisa as manifestações das novas tendências na América Latina e finaliza com a descrição de algumas iniciativas promovidas pela OPAS no sentido de aproveitar as oportunidades abertas pelas novas tendências para a melhoria das condições de saúde na região. Busca defender a tese de que a informação e o conhecimento são bens públicos essenciais e que as iniqüidades de acesso a esses bens são importantes determinantes das iniqüidades em saúde. Para que as políticas de saúde e as políticas de pesquisa em saúde se integrem e se consolidem como políticas públicas voltadas a atender ao interesse público e à promoção da eqüidade, é necessário o fortalecimento do processo democrático de definição das mesmas, multiplicando os atores envolvidos, os espaços e oportunidades de interação entre eles e instrumentando sua participação com o acesso eqüitativo a informações e conhecimentos científicos pertinentes que permitam a defesa fundamentada de seus interesses.

Palavras-chave Eqüidade, Pesquisa, Conhecimento, Participação social, Política de saúde, América Latina 


\section{Introdução}

As iniquiidades em saúde entre grupos e indivíduos, ou seja, as desigualdades de saúde, que além de sistemáticas e relevantes são também evitáveis, injustas e desnecessárias (Whitehead, 1992), são uma das características mais marcantes da situação de saúde da América Latina e do Caribe. De acordo com a Organização Pan-Americana da Saúde (OPS, 2002), a mortalidade infantil na América Latina em 2000 foi de 24,8 mortes por mil nascidos vivos, variando de 5,2 (Anguila) a 80,3 (Haiti). Ao final da década de 1990 um recém-nascido do quintil de mais baixa renda tinha em média um risco 2,9 vezes maior de falecer no primeiro ano de vida que um outro situado no quintil mais alto (42 e 14,5/1000, respectivamente).

Nos últimos anos observa-se um grande crescimento da literatura científica internacional dedicada ao estudo das iniqüidades em saúde e seus determinantes (Wing \& Richardson, 1999). Graças à consciência das limitações do enfoque de risco individual para análise dos problemas de saúde no nível populacional, novos marcos explicativos mais integrais e novas abordagens metodológicas vêm sendo adotadas (Susser, 1998; Krieger, 1994). Esse é o caso da chamada análise contextual ou multinível, que busca combinar a análise das características dos indivíduos com as dos grupos sociais a que pertencem. Este enfoque se fundamenta no reconhecimento de que os grupos sociais são unidades legítimas de análise; que as propriedades destes grupos são diferentes das dos seus membros individuais e que as variáveis grupais ou contextuais podem ter efeitos independentes das características individuais ou modificar a maneira como estas características individuais incidem sobre a situação de saúde (DiezRoux, 1998).

Nos últimos anos, aumentaram também em quantidade e qualidade os estudos sobre as relações entre a saúde das populações, as desigualdades nas condições de vida e o grau de desenvolvimento da trama de vínculos e associações entre indivíduos e grupos.

Entre os achados mais significativos desses estudos dois merecem ser destacados. O primeiro é a constatação de que uma vez superado um determinado limite de crescimento econômico de um país (cerca de 8.000 a 10.000 dólares per capita), um crescimento adicional da riqueza não se traduz em melhorias significativas das condições de saúde. A partir desse nível o fator mais importante para explicar a situação geral de saúde de um dado país não é sua riqueza total, mas a maneira como ela se distribui (Wilkinson, 1997). Em outras palavras, a desigualdade na distribuição de renda não é prejudicial à saúde somente dos menos favorecidos, como também da sociedade em seu conjunto.

O segundo importante achado da produção científica recente neste tema é haver identificado o desgaste do chamado capital social, ou seja, das relações de solidariedade e confiança entre pessoas e grupos, como um importante mecanismo pelo qual as iniqüidades de renda impactam negativamente a situação de saúde. Segundo vários autores, o desgaste do capital social em sociedades iníquas explicaria em grande medida por que sua situação de saúde é inferior à de sociedades em que as relações de solidariedade são mais desenvolvidas. Ao contrário do capital físico ou humano, que são bens privados, o capital social é um bem público, criado pelas relações sociais. A debilidade dos laços de coesão social ocasionada pelas iniqüidades de renda corresponde a baixos níveis de capital social e de participação política. Países com grandes iniqüidades de renda, escassos níveis de coesão social e baixa participação política são os que menos investem em capital humano e em redes de apoio social fundamentais para a promoção e proteção da saúde coletiva (Evans et al., 1994; Kawachi et al., 1997).

Um estudo bibliométrico de 576 artigos produzidos entre 1971 e 2000 e indexados em diferentes bases de dados revela que também na América Latina há um crescente interesse pelo tema das iniqüidades em saúde, já que a produção dos últimos sete anos ultrapassou a dos 23 anos anteriores. Além da concentração em determinados países, uma análise de conteúdo dessa produção permite observar que os estudos empíricos são relativamente pouco freqüentes em comparação com a riqueza e variedade dos modelos teóricos. Observa-se também uma grande diversidade de desenhos metodológicos juntamente com um importante desenvolvimento de estudos ecológicos e etnográficos (Almeida Filho et al., 2003).

Infelizmente os importantes avanços no conhecimento dos determinantes das condições de saúde e em particular das iniqüidades, tanto na literatura internacional como latino-americana, não se acompanham de um correspondente avanço na utilização desse conhecimento para a definição de políticas de saúde na região. 
Neste artigo procuraremos analisar as barreiras e dificuldades que limitam uma melhor utilização dos resultados da pesquisa para a formulação e implantação de políticas de saúde, especialmente aquelas voltadas para a promoção da eqüidade em saúde. Procuraremos também analisar algumas tendências e oportunidades para a superação dessas barreiras e dificuldades, assim como iniciativas em curso que buscam aproveitá-las, destacando algumas iniciativas promovidas pela Organização PanAmericana da Saúde.

\section{A produção e a utilização do conhecimento}

A situação da pesquisa na América Latina padece de uma série de deficiências quantitativas e qualitativas, além de uma grande concentração de recursos e da produção científica. Por exemplo, cerca de $70 \%$ dos gastos em $\mathrm{P} \& \mathrm{D}$ no ano de 2000 foram feitos pelo Brasil e Argentina. Com relação a gasto por habitante, os Estados Unidos gastam 40 vezes mais que o total dos países da região; Canadá, 18 vezes e Espanha, 7. Brasil e Argentina possuem dois terços dos pesquisadores da região. No que se refere à produção científica, a América Latina é responsável por apenas 3\% dos artigos incluídos na base de dados do Institute for Scientific Information (ISI), $60 \%$ dos quais produzidos por pesquisadores do Brasil e da Argentina. Em termos de produtividade, em 1999, os pesquisadores da América Latina publicaram 18,5 artigos por 100 pesquisadores, menos da metade dos pesquisadores espanhóis com 39,5 artigos por 100 . No caso da pesquisa em saúde, a situação é similar, uma vez que em 1998 a América Latina foi responsável por $2 \%$ dos artigos indexados em MEDLINE, 80\% dos quais da Argentina, Brasil e México (RICYT, 2002). Observase também um grande desequilíbrio na abordagem dos problemas de saúde, com grande predominância do enfoque individual. Apenas $3 \%$ dos artigos publicados em bases de dados internacionais podem ser classificados como pesquisa em saúde pública ou pesquisa de base populacional (Pellegrini, 2000).

Além dos problemas mencionados referentes à escassez e concentração de recursos e da produção científica, merece ser destacado um problema característico dos sistemas de C\&T da região e, em particular da C\&T em saúde, o qual por sua importância pode agravar ou im- pedir a solução de todos os demais. Trata-se da debilidade das relações entre a produção e a utilização do conhecimento que no caso da saúde se manifesta pela baixa utilização dos resultados de pesquisa para a definição de políticas e programas e para a produção de bens e serviços de saúde.

Este fenômeno da separação entre produção e utilização do conhecimento não é exclusivo dos países da América Latina, mas é especialmente acentuado na região, em função de raízes históricas que se discutirão em seguida. A falta de integração entre os processos de produção e utilização do conhecimento em última instância expressa uma debilidade das relações entre a ciência e os demais setores da sociedade. Além de impedir que os países da região utilizem plenamente seu já limitado potencial técnico-científico para a solução dos graves e complexos problemas de desenvolvimento econômico e social que enfrentam, esta debilidade de relações entre ciência e sociedade põe em risco a própria sobrevivência da infra-estrutura de pesquisa por torná-la um alvo bastante vulnerável aos cortes de gastos públicos dos quais depende quase que exclusivamente.

A intervenção institucionalizada e consistente do Estado no desenvolvimento da C\&T na América Latina praticamente começa no inicio dos anos 70 com a criação dos Conselhos de C\&T ( $\operatorname{anos} 50$, no caso do Brasil e Argentina). Seja pela predominância de um modelo de desenvolvimento protecionista pouco favorável às atividades de $C \& T$ por não estimular a qualidade, competitividade e criatividade, seja pelo vínculo demasiado estreito e exclusivo com a comunidade científica e as universidades, esses conselhos de C\&T não conseguiram influenciar as demais instâncias do Estado, nem empolgar outros setores da sociedade. Seus planos estavam fortemente marcados por um enfoque "ofertista", ou seja, limitavam-se ao fomento da capacidade científica nacional (da “oferta”), com pouca preocupação por responder a demandas derivadas do entorno social, econômico e político. Some-se a isso uma visão centralizadora do planejamento, despreocupada em construir as condições necessárias para a realização de seus objetivos e o resultado não poderia ser outro senão a crônica debilidade das relações entre C\&T e o setor de produção de bens e serviços (Pellegrini, 2000).

No caso da baixa utilização de resultados de pesquisa para a definição de políticas, além das raízes históricas mencionadas, há causas mais 
específicas em grande medida derivadas de concepções errôneas sobre o processo de tomada de decisões e sobre as relações entre este e a pesquisa. Em geral, concebem-se ambos os processos, o de produção de conhecimento e o de tomada de decisão, como processos separados, com lógicas, agentes e espaços institucionais específicos. De fato, isto é o que em geral ocorre na prática, obrigando a um enorme esforço para fazer convergir o que nasceu e se desenvolveu de maneira independente. Alguns autores chamam a transferência a posteriori de resultados de pesquisa para a tomada de decisões como "a difícil tradução" (Bronfman et al., 2000). Como se verá mais adiante essa transferência não deve ser necessariamente difícil, podendo, pelo contrário, ser uma construção conjunta, interativa, fluida, entre os atores envolvidos nos dois processos.

O processo de decisão que leva à definição e implantação de políticas é, em geral, entendido como um processo linear, que compreende várias etapas seqüenciais como a identificação do problema, análise de suas causas, mapeamento de alternativas de solução, seleção de uma dessas alternativas, desenho da política, implementação, seguimento, avaliação, etc. Essas etapas obrigam a uma série de decisões tomadas por um ator privilegiado, o "tomador de decisão", que atua de maneira racional, utilizando a melhor informação disponível. De acordo com essa concepção, o problema da transferência de resultados de pesquisa se resume a uma aproximação entre dois atores centrais, o "tomador de decisão", por um lado, e o pesquisador, por outro, para que este faça chegar ao tomador de decisão a informação necessária em formato adequado e no momento oportuno, de modo que sua decisão seja cientificamente fundamentada, ou evidence based. Abundante literatura se ocupa de como fazer essa aproximação, como superar barreiras de tempo com produtos intermediários de pesquisa, como superar barreiras de comunicação com o uso de linguagem apropriado, etc.

Na realidade o processo de definição de políticas não obedece a este modelo ideal. Em lugar do "tomador de decisão" fazendo escolhas racionais em maior ou menor grau baseadas em evidência, o que se observa é um processo bastante mais complexo que envolve diversos atores, com interesses diferenciados e por vezes contraditórios. Reconhecendo o caráter essencialmente político desse processo, a promoção de uma maior utilização de resultados de inves- tigação para a definição de políticas implica instrumentar a atuação dos diferentes atores, particularmente dos que usualmente estão excluídos do processo de decisão, buscando diminuir as enormes iniqüidades de acesso a informações e conhecimentos.

As iniqüidades de acesso a conhecimentos e informações são especialmente dramáticas, pois ao reforçar a exclusão, têm um enorme poder de gerar e ampliar outras iniqüidades. No caso da saúde, as iniqüidades de informação podem ser consideradas um importante determinante das iniqüidades de saúde, na medida em que o acesso iníquo a conhecimentos e informações prejudica a atuação individual e coletiva dos membros de uma sociedade para a mudança de estruturas, comportamentos e políticas. $\mathrm{O}$ acesso universal à informação deve portanto ser parte essencial do processo de definição de políticas de saúde voltadas para a eqüidade.

Para definir estratégias, canais e oportunidades que permitam disseminação ampla de resultados de pesquisa é necessário conhecer os diversos atores sociais, identificando as fontes de informação em que cada um deles confia, que tipo de informação lhes interessa, como avaliam a informação, que motivações têm para tomar decisões específicas e com quem interagem, competem ou se aliam (Bronfman \& Trotsle, 2000).

Não há portanto nenhuma contradição entre, por um lado, a promoção de políticas baseadas em evidência e, por outro, a ampliação da participação social na definição das mesmas, pois ambos os processos se reforçam mutuamente. Entretanto, para que haja uma maior participação social na definição de políticas de saúde é também necessário romper com o processo tradicional de definição de agendas e políticas em círculos de decisão restritos e multiplicar os espaços para a expressão dos diferentes interesses e a construção de consensos, o que, em última análise, significa o aperfeiçoamento das instituições democráticas das sociedades da região.

Os países da América Latina enfrentam, portanto, o duplo desafio de desenvolver e fortalecer a capacidade de gerar, interpretar e adaptar novos conhecimentos e tecnologias e ao mesmo tempo, criar os espaços de ajustes democráticos que permitam que esta capacidade se ponha, de maneira eqüitativa, a serviço da melhoria da saúde dos povos da região.

Como se verá a seguir, estão ocorrendo, em nível mundial, profundas transformações no 
modo de produção de conhecimentos e nas relações entre ciência e sociedade que se constituem em excelentes oportunidades para enfrentar o desafio e estreitar as relações entre pesquisa de saúde, política de saúde e eqüidade nos países da região.

\section{Novas tendências e oportunidades}

Conforme se mencionou anteriormente, a informação e o conhecimento científico e a superação das iniqüidades em seu acesso são essenciais para a democratização do processo de formulação de políticas de saúde. Entretanto, algumas perguntas se impõem: A que tipo de informação e conhecimento científico estamos nos referindo? Como organizar uma agenda de pesquisa que permita a produção de informações e conhecimentos que sejam efetivamente relevantes para solucionar os problemas de saúde? Como fazer para que ambos os processos, o de produção de conhecimentos e o de formulação de políticas, caminhem de maneira articulada em todas suas etapas e não separado, como tradicionalmente ocorre?

Nas três ou quatro últimas décadas e de maneira mais importante a partir do início dos anos 90, observam-se significativas mudanças nas relações entre ciência e sociedade que ajudam a responder a essas perguntas. Entre as mudanças destaca-se o que se poderia chamar de passagem da segregação à integração. A ciência percorreu um longo caminho para criar um espaço social próprio com instituições, métodos e um ethos marcado pelos princípios de universalidade, desinteresse, "comunalismo" e ceticismo organizado. Desta maneira pode afirmar-se como uma prática social autônoma e defender-se de influências e restrições impostas pela religião ou o poder militar. Nas últimas décadas, a comunidade científica e as instituições científicas que estavam firmemente unidas por valores, práticas e formas de organização, passaram a se integrar cada vez mais com outros setores da sociedade, o que trouxe como conseqüência a participação da cidadania na definição de agendas e na avaliação das atividades de investigação.

Outra mudança significativa nas relações entre ciência e sociedade diz respeito aos critérios de validação do conhecimento científico. Ao abandonar a busca da verdade absoluta, assumindo a provisão dos seus resultados, a ciência passou a buscar a produção do conheci- mento confiável, ou seja, aquele capaz de ser validado pelo consenso da comunidade científica, a qual é auto-suficiente para estabelecer os critérios de confiabilidade, que se baseiam principalmente na contestação de resultados. Recentemente, graças a esse processo de integração e contextualização da ciência, vem-se afirmando o conceito de conhecimento socialmente robusto, ou seja, o conhecimento que não se limita à validação por uma comunidade restrita, mas requer a validação de uma comunidade mais ampla preocupada não apenas com a confiabilidade do conhecimento, como também com suas implicações sociais (Nowotny et al., 2001).

Essas importantes mudanças são conseqüência de transformações ocorridas tanto no âmbito da própria ciência, como no nível da sociedade. Respondendo à dinâmica intrínseca de desenvolvimento da ciência e às influências de seu entorno, o modo de produção do conhecimento vem sofrendo importantes mudanças no que se refere a seus objetos, locus institucionais, enfoques conceituais/metodológicos e outras características que serão analisadas mais adiante. Por outro lado, no que tange à sociedade, as mudanças nos processos produtivos com a substituição da produção em massa por processos flexíveis altamente dependentes de conhecimento e inovação, as mudanças nas relações entre Estado e sociedade civil e outros processos que caracterizam o surgimento das chamadas "sociedades do conhecimento", contribuem de maneira bastante significativa para a maior fluidez nas relações entre ciência e sociedade.

Conforme se mencionou, o modo de produção do conhecimento vem passando por significativas transformações que redefinem a maneira como se estabelecem as agendas de pesquisa, os arranjos institucionais nos quais se desenvolvem as atividades de pesquisa, os critérios de validação do conhecimento e em particular os modos de transferência/disseminação/utilização do conhecimento, com importantes implicações para o tema que nos ocupa das relações entre pesquisa e política de saúde. Gibbons e outros autores identificam o surgimento de um novo modo de produção do conhecimento ao qual denominam "socialmente distribuído" ou "modo 2" (Gibbons et al., 1994).

Vários são os aspectos que distinguem o "modo 2" do modo tradicional ou "modo 1". No que se refere ao locus principal onde se produz o conhecimento, no caso do "modo 1 " as 
universidades e as instituições públicas de pesquisa ocupam o lugar de destaque, enquanto no "modo 2" a produção do conhecimento se desenvolve principalmente por meio de arranjos flexíveis, não-hierárquicos e transitórios entre instituições de diversos tipos organizadas em redes de colaboração. Esses novos arranjos institucionais são em grande medida facilitados e promovidos pelas novas tecnologias de informação e comunicação.

As agendas de pesquisa no "modo 1" são definidas basicamente pelos investigadores em função do desenvolvimento de suas respectivas disciplinas. No "modo 2 " as agendas são definidas em espaços de intercâmbio chamados "contexto de aplicação", em que vários atores interagem para a identificação de problemas de interesse comum. Nas palavras de Gibbons, em um novo modo de produção do conhecimento socialmente distribuído os problemas são formulados e a pesquisa se desenvolve em contexto voltado para a solução de problemas, envolvendo uma complexa interação entre especialistas, usuários e financiadores.

É importante destacar que esta alternativa ao "elitismo" acadêmico característico do "modo 1" não deve ser identificada com uma "democracia vulgar", na qual os projetos ou linhas de pesquisa prioritárias seriam selecionados por votação da maioria. Segundo Kitcher, dessa forma correríamos o risco de cair numa "tirania da ignorância", onde as preferências populares seriam ditadas pelo impulso ou pela ignorância, levando a que projetos de alta relevância do ponto de vista epistêmico fossem desprezados em favor de uma percepção de curto prazo, o que em nada ajudaria para aumentar a contribuição da ciência para o bem-estar coletivo (Kitcher, 2001). O dilema entre o elitismo e a democracia vulgar ou tirania da ignorância é falso, pois como veremos mais adiante está se desenvolvendo e aperfeiçoando uma série de mecanismos de participação que permitem o exercício de uma democracia esclarecida, na qual as decisões sobre políticas e prioridades sejam feitas por cidadãos bem informados e representantes dos mais diferentes setores da sociedade.

Por motivos históricos, próprios da conjuntura pós-guerra nos EUA, no "modo 1" reconhecem-se dois tipos fundamentais de pesquisa propostos por Vannevar Bush em 1945 (Bush, 1990) e referendados na reunião de Frascati que deu origem ao manual do mesmo nome (Stokes, 1997): a pesquisa básica, compro- metida exclusivamente com o avanço do conhecimento (conhecer para entender) e a pesquisa aplicada, comprometida com a solução de problemas (conhecer para utilizar), ambas competindo entre si por recursos de todo tipo. No "modo 2" essa distinção não se justifica, uma vez que o tipo de pesquisa a ser desenvolvida é aquela necessária à solução do problema identificado no contexto de aplicação, incluindo desde a pesquisa mais fundamental até a operacional. A natureza dos problemas próprios do "modo 2" obriga uma abordagem transdisciplinar dos mesmos, enquanto no "modo 1" tanto a origem dos problemas como os conceitos e metodologias para enfrentá-los em geral se restringem a uma dada disciplina.

A relação entre produtores e usuários do conhecimento, no "modo 1", se estabelece eventualmente pela transferência unidirecional e a posteriori de resultados. No "modo 2", a relação entre os diversos atores que participam do contexto de aplicação é fluida e regular, permeando todas as etapas do processo, desde a definição do problema até a interpretação, avaliação e utilização de resultados. O contexto de aplicação se transforma ao mesmo tempo em um cenário de aprendizagem, aproximando os códigos de produtores e utilizadores do conhecimento através de uma prática comum.

No "modo 1", o mérito científico avaliado por pares é o mais importante, senão o único critério de avaliação de mérito ou qualidade, enquanto no "modo 2 " o controle de qualidade inclui maior variedade de critérios que se referem tanto ao mérito científico como à pertinência e relevância do conhecimento produzido avaliado por pares e ímpares. Como mencionado anteriormente trata-se da passagem do conhecimento confiável para o conhecimento socialmente robusto.

O principal veículo de divulgação de resultados, no "modo 1", é a revista científica que circula basicamente entre a própria comunidade científica. Já "no modo 2" diversos meios são utilizados para alcançar a todos os interessados. No "modo 1 " o financiamento das atividades de pesquisa se faz principalmente com recursos públicos, enquanto no "modo 2 " há uma maior diversidade de fontes públicas e privadas.

Finalmente, como corolário de todo o anterior, neste novo modo de produção de conhecimento as decisões não podem ser tomadas de maneira centralizada nos organismos de C\&T a que poucos têm acesso. Para ser coerente com 
seus princípios, as decisões sobre agendas, prioridades e outros aspectos da gestão de C\&T no âmbito deste novo modo de produzir conhecimento requerem a criação e multiplicação de contextos de aplicação, ou seja, de espaços e oportunidades para a interação de diversos atores e o estabelecimento de consensos e redes de cooperação entre eles.

Reconhecemos que esta descrição do "modo 1 " e "modo 2" é por demais esquemática e que na prática se observa um número infinito de situações intermediárias e fases de transição. Sem pretender aprofundar ainda mais esta visão esquemática, mas buscando atender a fins puramente didáticos, resume-se no quadro 1 as principais características desses dois tipos polares ideais de modos de produção do conhecimento.

\section{Novas tendências e oportunidades na América Latina e a cooperação técnica da OPAS}

As novas tendências e oportunidades representadas pelo modo de produção de conhecimento socialmente distribuído se expressam também na América Latina de maneira ainda relativamente tímida, mas bastante evidente.

Um bom exemplo de tendência em direção ao "modo 2" na América Latina é o seqüencia- mento do genoma da Xylella fastidiosa por uma rede de 34 laboratórios de São Paulo, envolvendo mais de 200 pesquisadores e publicado na revista Nature em julho de 2000. O problema de pesquisa foi colocado pela indústria cítrica que estava sofrendo perdas de cerca de 30\% dos cultivos de laranjas por cauda da bactéria. Esta foi a primeira publicação do genoma de um patógeno vegetal e desde então os pesquisadores brasileiros vêm recebendo manifestações de reconhecimento mundial tanto da comunidade científica como de setores governamentais e empresariais. Agências do governo americano solicitaram apoio dos pesquisadores brasileiros para seqüenciar o genoma de uma cepa desta mesma bactéria que está atacando as plantações de uva da Califórnia, causando sérios prejuízos (Trafford, 2001).

A chave desse sucesso foi a sábia decisão da Fundação de Amparo à Pesquisa do Estado de São Paulo (FAPESP) de criar um instituto virtual de genômica e bioinformática a partir de laboratórios já existentes, evitando o caminho tradicional que seria construir um novo instituto de pesquisa em genética. Em lugar de tijolos e paredes, os recursos foram destinados a fortalecer os laboratórios existentes com a compra de seqüenciadores e computadores e o treinamento de recursos humanos. A rede inclui hoje mais de 50 centros em todo o país cujos investigadores envolvidos em diferentes

Quadro 1

Modos de produção do conhecimento (Gibbons et al., 1994).

\begin{tabular}{|c|c|c|}
\hline & Tradicional (Modo 1) & Socialmente distribuído (Modo 2) \\
\hline $\begin{array}{l}\text { - Locus de produção } \\
\text { do conhecimento }\end{array}$ & $\begin{array}{l}\text { - Instituições com paredes, } \\
\text { principalmente universidades } \\
\text { e instituições de pesquisa }\end{array}$ & $\begin{array}{l}\text { - Redes de colaboração entre } \\
\text { instituições de diversa natureza }\end{array}$ \\
\hline - Agenda de investigação & $\begin{array}{l}\text { - Agendas definidas por pesquisadores } \\
\text { em função do desenvolvimento } \\
\text { de suas disciplinas }\end{array}$ & $\begin{array}{l}\text { - Agendas definidas em contextos } \\
\text { de aplicação }\end{array}$ \\
\hline - Tipos de pesquisa & $\begin{array}{l}\text { - Básica (conhecer para entender) vs. } \\
\text { Aplicada (conhecer para utilizar) }\end{array}$ & - Solução de problemas \\
\hline - Enfoque & - Disciplinar & - Transdisciplinar \\
\hline $\begin{array}{l}\text { - Relação entre produtores } \\
\text { e usuários do conhecimento }\end{array}$ & $\begin{array}{l}\text { - Transferência unidirecional } \\
\text { a posteriori de conhecimentos } \\
\text { e tecnologias }\end{array}$ & $\begin{array}{l}\text { - Intercâmbio permanente } \\
\text { de conhecimentos e tecnologias }\end{array}$ \\
\hline - Critérios de avaliação & • Mérito científico & - Mérito científico e relevância social \\
\hline - Meios de disseminação de resultados & - Revista científica & • Múltiplos meios \\
\hline - Financiamento & - Recursos públicos & $\begin{array}{l}\text { - Diversidade de fontes públicas } \\
\text { e privadas }\end{array}$ \\
\hline - Gestão da atividade científica & - Planejamento centralizado & - Criação de espaços de interação \\
\hline
\end{tabular}


projetos se comunicam e intercambiam resultados diariamente pela Internet. É uma clara demonstração de como novas formas de organização da atividade científica podem multiplicar a capacidade científica de um país e melhor aproveitar seu potencial para resolver problemas econômicos e sociais.

Além deste exemplo, observa-se uma série de tendências na região que também apontam para uma nova maneira de organizar a atividade científica. Entre estas se destacam algumas experiências de definição de agendas de pesquisa através de processos participativos; o estabelecimento de alianças entre organismos do governo e do setor privado para o financiamento e execução de pesquisas; o estabelecimento de sistemas de avaliação da produção científica que levam em conta a pertinência e relevância além do mérito científico; as iniciativas de descentralização das atividades de C\&T e o fortalecimento de acordos de cooperação regional.

Algumas universidades da região vêm buscando reorganizar suas relações externas com a criação de redes de colaboração com institutos de pesquisa, consultoras, empresas e incubadoras de empresas com quem estabelecem relações em função de projetos específicos, o que repercute internamente obrigando a uma revisão de suas tradicionais formas de organização por departamentos e disciplinas. Da mesma maneira, as organizações públicas de ciência e tecnologia em saúde, que possuem grande tradição na região, como é o caso da Fundação Oswaldo Cruz (Fiocruz) do Brasil, estão promovendo a reconversão de suas estruturas e formas de atuação, para fazer frente às exigências de maior eficiência e competitividade e ao mesmo tempo manter-se sintonizadas com as novas tendências mundiais de desenvolvimento técnico-científico. Para enfrentar esse desafio várias dessas organizações estão buscando maior autonomia e flexibilidade administrativa, definindo mecanismos e critérios de avaliação de impacto social de suas atividades e desenvolvendo sua capacidade de gestão tecnológica para negociar contratos de transferência de tecnologia e acordos de cooperação.

A Organização Pan-Americana da Saúde (OPAS) vem desenvolvendo uma série de iniciativas para fortalecer as tendências mencionadas. Essas iniciativas se articulam em uma estratégia de cooperação denominada DECIDES, abreviatura de Democratizando o Conhecimento e a Informação para o Direito à Saú- de. DECIDES busca democratizar o conhecimento e a informação, entendendo por democratização do conhecimento não apenas sua divulgação, como costuma ocorrer, mas, em um sentido muito mais amplo, a participação social em todas etapas de sua produção, disseminação e utilização, assim como na própria gestão da atividade científica. Como o próprio acrônimo DECIDES indica, a democratização do conhecimento entendida desta maneira "empodera" os cidadãos, permitindo que participem das decisões relativas à definição e implantação de políticas que lhes garantam o alcance do direito à saúde.

Entre as iniciativas desenvolvidas no âmbito de DECIDES está a coordenação e apoio financeiro a projetos de pesquisa multicêntricos nos quais vários grupos de pesquisa de diversos países trabalham em um mesmo projeto de pesquisa, cujo protocolo foi desenvolvido conjuntamente com um enfoque multidisciplinar. Esses projetos multicêntricos aportam conhecimentos originais sobre problemas de alta relevância para a saúde pública da região e seus resultados possuem importantes implicações para a formulação de políticas. Sua importância deriva também do processo pelo qual se desenvolvem, permitindo o estabelecimento de redes de colaboração entre os grupos participantes.

Nos últimos cinco anos foram apoiados vários desses projetos, destacando-se entre eles um projeto sobre "Atitudes e comportamentos violentos" com base em pesquisas domiciliares em oito cidades da América Latina e Madri; "Saúde, bem-estar e envelhecimento" também baseado em pesquisas domiciliares em sete países; "Macrodeterminantes das iniqüidades de saúde", a partir de dados secundários de pesquisas domiciliares de cinco países; "Comportamentos dietéticos e de exercício" em quatro países do Caribe inglês; "Qualidade dos serviços radiodiagnóstico", envolvendo a mais de 180 físicos, médicos e radiologistas de quatro países latino-americanos; "Gastos da atenção à saúde decorrentes do uso de tabaco" em quatro países e "Avaliação de intervenções para a prevenção da desnutrição em crianças", também em quatro países.

Outras iniciativas de cooperação técnica da OPAS que visam promover as novas tendências no modo de produção do conhecimento estão relacionadas com a promoção do uso intensivo das novas tecnologias de comunicação e informação. Estas tecnologias oferecem extraordi- 
nárias oportunidades para a ampla disseminação e diminuição das iniqüidades de acesso à informação científica em saúde, que como foi mencionado, são em grande medida responsáveis pelas enormes iniqüidades em saúde observadas na região. O grande desafio é como incorporar e dominar essas tecnologias de maneira que seu potencial efetivamente se realize e que as iniqüidades não se ampliem. A OPAS, aproveitando a experiência acumulada por BIREME e pelo Sistema Latino-americano de Informação em Ciências da Saúde que ela coordena, está buscando enfrentar este desafio, promovendo a democratização da informação e do conhecimento através da criação da Biblioteca Virtual em Saúde (BVS) <www.bireme.br $>$.

Operada na Internet, a BVS é um espaço virtual no qual se incluem as mais variadas e relevantes fontes de informação técnico-científicas em texto completo, juntamente com bases de dados numéricas, diretórios, instrumentos multimídias de apoio à educação e à tomada de decisão, notícias e listas de discussões, etc. Ao mesmo tempo em que é uma coleção organizada de fontes de informação em formato digital com capacidade de armazenagem infinita, propiciando acesso universal em tempo real, a BVS é também uma plataforma virtual que permite interações entre produtores, intermediários e usuários do conhecimento, constituindo-se efetivamente em um contexto de aplicação para análise e identificação de problemas, intercâmbio de conhecimentos e tomada de decisão coletiva.

Um dos produtos desenvolvidos no âmbito da BVS com o objetivo de ampliar a divulgação da produção científica latino-americana é o projeto SciELO (Scientific Electronic Library on Line). Consiste na publicação em formato eletrônico e texto completo de todos os números publicados nos últimos cinco anos pelas principais revistas científicas da América Latina, incluindo indicadores sobre seu uso e impacto <www.scielo.org $>$ (Packer, 1998).

Com o objetivo de promover e apoiar na região uma gestão da atividade científica em saúde baseada, ao mesmo tempo, em dados e evidências e na participação dos diversos atores envolvidos nessa atividade, a OPAS está construindo uma BVS específica de ciência e saúde (BVS/CyS). Entre os diversos componentes da BVS/CyS destacam-se o componente de saúde da Plataforma ScienTI e as Conferências de Consenso Cidadão.
A Plataforma ScienTI, construída através da Rede ScienTI, da qual participam os organismos de C\&T de mais de dez países, grupos de P\&D em ciências da informação, organismos internacionais e outros atores, inclui uma serie de informações de apoio à gestão da C\&T como informações sobre currículos de pesquisadores; diretórios de grupos e instituições; agências e programas de financiamento de atividades de pesquisa em saúde; projetos em curso; indicadores de infra-estrutura, recursos e produção científica. Entre estas informações merece destacar-se a base de currículos que já está em plena implantação em vários países da região, a partir da Plataforma Lattes desenvolvida pelo CNPq do Brasil. Trata-se de um formato único de currículo com vínculos eletrônicos com a SciELO e outras bases bibliográficas que será de grande utilidade para promover maior colaboração e intercâmbio entre investigadores em nível nacional e regional, identificação de especialistas, desenvolvimento de projetos colaborativos, concessão de bolsas e estágios, revisão por pares internacional, cursos colaborativos, etc.

Outro componente da BVS/CyS são as Conferências de Consenso Cidadão (CCC). Vários autores vêm manifestando preocupação pela participação cada vez menor do chamado cidadão comum no debate e no processo de tomada de decisões sobre temas considerados complexos. Há uma tendência cada vez maior de considerar que somente os especialistas são capazes de tratar destes temas, o que limita a diversidade de opiniões, debilita a consciência cívica e põe em perigo a vitalidade da democracia que deve alimentar-se de um vigoroso intercâmbio de idéias e opiniões (Lasch, 1995). Segundo Edgar Morin esta tendência se deve à crescente complexidade dos problemas e à maneira reducionista e fragmentada de enfrentálos. A superespecialização e a fragmentação do conhecimento institui o reino dos especialistas, criando uma brecha cada vez maior entre os que sabem e os ignorantes, ou seja, entre os especialistas e os cidadãos em seu conjunto (Morin, 1996).

As CCC são parte da resposta a essas preocupações, pois ampliam o debate sobre temas de ciência e tecnologia, usualmente circunscrito a especialistas e grupos de interesses organizados, ao permitir a inclusão dos pontos de vista do público em geral. As experiências desenvolvidas a partir de meados dos anos 90 inicialmente na Dinamarca pelo Danish Board of 
Technology e posteriormente nos demais países escandinavos, França, Austrália, EUA e outros mostram que os participantes das CCC, apesar de não possuírem um conhecimento prévio sobre o tema, conseguem desenvolver um alto grau de compreensão de seus mais diversos e complexos aspectos, através de um processo de capacitação e discussão com metodologia apropriada, produzindo relatórios de grande valor para a definição de políticas e estabelecimento de normas e regulações (Joss \& Durand, 1995).

As Conferências de Consenso têm sido utilizadas para a discussão de temas relacionados a avanços científicos e tecnológicos de ponta com alto impacto social, que requerem a elaboração de pautas éticas, normas e legislação que regulem seu desenvolvimento e incorporação. Exemplos destes temas são os alimentos transgênicos, clonagem, diagnóstico genético e outros. Nada impede, no entanto, que outros temas ligados às relações entre pesquisa e política na área de saúde sejam também tratados por meio desta metodologia. A BVS/CyS busca aproveitar esta experiência internacional acumulada com as CCC, promovendo adaptação de sua metodologia à realidade dos países da região e introduzindo o uso intensivo das novas tecnologias baseadas na Internet para a execução de algumas etapas da conferência.

\section{Conclusão}

Entre as importantes mudanças nas relações entre ciência e sociedade principalmente a partir da segunda metade do século 20 , além das mencionadas anteriormente, está a passagem da certeza à incerteza. A certeza de que caminhávamos inexoravelmente para um mundo melhor, onde o avanço científico-tecnológico centralmente planificado nos levaria a resolver os problemas do desenvolvimento, do atraso e da miséria, deu lugar a uma concepção muito mais realista, mais consciente da complexidade dos problemas, dos limites do planejamento e da própria ciência. Aprendemos que os avanços científico-tecnológicos abrem enormes oportunidades, mas que seu potencial só se realiza se acompanhados por uma ampla e diversificada gama de inovações sociais.

Este é o caso, por exemplo, das novas tecnologias de informação e comunicação. Como vimos, elas permitem o desenvolvimento e consolidação de um novo modo de produção do conhecimento mais comprometido com a solução de problemas de alta relevância social e, no caso da saúde, abrem excelentes oportunidades para a superação das iniqüidades de saúde. Em primeiro lugar, por sua capacidade de influenciar importantes determinantes gerais de saúde como são as relações sociais, os processos culturais e outros aspectos fortemente relacionados com o bem-estar físico, mental e social. Em segundo lugar, por exercer um importante impacto sobre as iniqüidades em saúde na medida em que permitem ampliar o acesso à informação por parte de grupos excluídos dos processos de tomada de decisões de qualquer tipo, trazendo como conseqüência o "empoderamento" desses grupos, sua constituição como atores sociais e, em última instancia, o fortalecimento do próprio processo democrático.

Entretanto, todo este potencial está ameaçado de não se realizar se não se resolve um problema fundamental que são as iniqüidades de acesso a essas tecnologias, usualmente chamadas de brecha digital ou digital divide, a qual, como vimos, é mais dramática que qualquer outra iniqüidade, tendo um poder para gerar e ampliar outras iniqüidades. Os usuários da Internet nos países de América Latina ainda correspondem a uma pequena minoria da população geral, cerca de 5\%, embora o crescimento da conectividade na região seja dos mais altos do mundo, estimando-se que em 2003 o número de usuários da Internet na região chegará a quarenta milhões, cerca de 7\% da população total (OECD, 2001).

A própria revolução eletrônica que atualmente é responsável por mais esta iniqüidade pode também contribuir para seu desaparecimento. Para aumentar sua rede de comunicações os países em desenvolvimento não devem necessariamente repetir os grandes investimentos feitos pelos países mais desenvolvidos, podendo utilizar novas tecnologias sem cabo que exigem menos investimento e manutenção. Os telefones celulares, há pouco tempo símbolo de status, permitem hoje estender a comunicação a lugares onde os cabos de cobre tardariam muitos anos a chegar. Não é absurdo imaginar que novos produtos de baixo custo como minicomputadores, que se ajustam à palma da mão e permitem acesso à Internet em qualquer lugar, em alguns anos serão utilizados nas escolas como se faz hoje com as calculadoras manuais que até há pouco também tinham preços proibitivos. 
O aproveitamento dessas e outras oportunidades para superar o problema das iniqüidades de informação depende do estabelecimento de políticas explicitamente desenhadas para tal. Essas políticas devem se basear no reconhecimento de que o conhecimento, a informação e a Internet são bens públicos e portanto devem ser objeto de políticas públicas. Com o avanço da globalização, em grande medida facilitada pelas próprias Tecnologias de Informação e Comunicação (TIC), estes bens públicos tendem, cada vez mais, a se transformarem em bens públicos globais, o que obriga que as políticas que estimulam sua criação e distribuição sejam objeto de novos arranjos institucionais da comunidade internacional, incluindo um novo papel de instituições multilaterais como as agências das Nações Unidas, onde se inscrevem a OPAS e a OMS (Stieglitz, 1999). As metas da reunião de Cúpula do Milênio, organizada pela ONU em 2001, reconhecem que o acesso à informação é um direito básico, comprometendo-se os países signatários a assegurar que os benefícios das novas tecnologias de informação e comunicação sejam postos à disposição de todos.

Como vimos, a BVS é um bom exemplo deste novo papel dos organismos internacionais em atuação conjunta com as instituições nacionais. Promovendo o intercâmbio deste bem público global que é a informação para o desenvolvimento social e para a saúde, em par- ticular, a BVS se constitui em um poderoso instrumento para promover a ação coletiva em busca da eqüidade.

Ao longo deste artigo buscamos defender a idéia de que a aproximação entre pesquisa em saúde e políticas de saúde com vistas à promoção da eqüidade não significa a despolitização das decisões sobre políticas em nome de uma racionalidade centralizadora baseada em evidência científica. Também defendemos a idéia de que a ciência, antes "externa” ao processo decisório, situada que estava na posição de árbitro legitimador cuja autoridade era intocável e inconteste, passa a participar do mesmo, submetendo-se tanto às agendas de pesquisa, como à avaliação de resultados e à própria substância do método científico, às expectativas públicas tradicionalmente consideradas "fora" do sistema científico.

Como consideração final para que as políticas de saúde e as políticas de pesquisa em saúde se integrem e se consolidem como políticas públicas voltadas a atender ao interesse público e à promoção da equidade, é necessário o fortalecimento do processo democrático de definição destas políticas, multiplicando os atores envolvidos, os espaços e oportunidades de interação entre eles e instrumentando sua participação com o acesso eqüitativo a informações e conhecimentos pertinentes que permitam a defesa fundamentada de seus interesses. 


\section{Referências bibliográficas}

Almeida-Filho N, Kawachi I, Pellegrini AP \& Dachs N 2003. Research on health inequities in Latin America and the Caribbean: bibliometric analysis (19712000) and descriptive content analysis (1971-1995). American Journal of Public Health 93:2037-2043.

Bronfman $\mathrm{M}$ et al. 2000. De la investigación en salud a la política: la difícil traducción. Editorial Manual Moderno. Santa Fé de Bogotá.

Bush V 1990. Science: the endless frontier. Washington DC, NSF, 4th anniversary ed.

Diez-Roux AV 1998. Bringing context back into epidemiology: variables and fallacies in multilevel analysis. American Journal of Public Health 88(2):216-222.

Evans R, Barer M \& Marmor T 1994. Why are some people healthy and others not? Aldine de Gruyter, Nova York.

Gibbons et al. 1994. The new mode of production of knowledge. DD. Sage, Londres.

Joss S \& Durant J 1995. Public participation in science: the role of consensus conferences in Europe. Science Museum, Londres.

Kawachi I, Kennedy B, Lochner K \& Prothrow-Stith D 1997. Social capital, income inequality and mortality. American Journal of Public Health 87:1491-1498.

Kitcher P 2001. Science, truth and democracy. Oxford University Press, Nova York.

Krieger N 1994. Epidemiology and the web of causation: has anyone seen the spider? Social Sciences and Medicine 39(7):887-903.

Lasch C 1995. The revolt of the elites and the betrayal of democracy. W.W. Norton Company, Nova York.

Morin E 1996. Ciência com consciência. Ed. Bertrand, Rio de Janeiro.
Nowotny et al. 2001. Re-thinking science: knowledge and the public in an age of uncertainty. Polity Press, Cambridge, Reino Unido.

OECD 2001. Understanding the digital divide. Disponível em $<$ www.oecd.org $>$.

Organização Pan-Americana da Saúde 2002. La salud en las Américas. Publicación Científica y Técnica No. 587, Washington, DC.

Packer A 1998. SciELO: uma metodologia para publicação eletrônica. Ciência da Informação 27(2).

Pellegrini Filho A 2000. Ciencia en pro de la Salud. Publicación Científica y Técnica No. 578. OPS/OMS, Washington DC.

RICYT Red Iberoamericana de Indicadores de Ciencia y Tecnología 2002. <www.ung.edu.ar/ricyt/>.

Stieglitz J 1999. Knowledge as a global public good. In Global public goods. UNDP, Oxford University Press, Nova York.

Stokes D 1997. Pasteur's Quadrant: basic science and technological innovation. Donnely and Sons, Virginia.

Susser M 1998. Does risk factor epidemiology put epidemiology at risk? Peering into the future. Journal of Epidemiology and Community Health 52:608-611.

Trafford A 2001. California vintners put hopes in Brazil's labs, p. A1. The Washington Post. Decembre 29.

Whitehead M 1992. The concepts and principles of equity and health. Inteational Journal of Health Services 22:430-445.

Wilkinson R 1997. Unhealthy societies. Routledge, Nova York.

Wing S \& Richardson D 1999. Material living conditions and health in the United States, Canada and Western Europe: a review of recent literature. Série Investigaciones en Salud Pública, No. 9, OPS, Coordenação de Investigações, Washington, 1998.

Artigo apresentado em 8/12/2003

Aprovado em 17/2/2004

Versão final apresentada em 2/3/2004 